\title{
The management of stress-strain state of the bases for stabilizing uneven settlements
}

\author{
Armen Ter-Martirosyan ${ }^{1}$, and Vitalii Sidorov, ${ }^{1, *}$ \\ ${ }^{1}$ Moscow State University of Civil Engineering, Yaroslavskoe shosse, 26, Moscow, 129337, Russia
}

\begin{abstract}
One of the actual problems of modern construction is the development of methods for managing the stress state of the soil bases for its use in conditions favorable to the construction. Also, soil state management methods are used to protect existing buildings and structures from the negative impacts of new construction. One of the methods that can affect the stress-strain state is the technology of compensatory injection. The essence of the method consists in injecting an extra volume of a slowly hardening solute into the soil base placed in the path of propagation of an impact wave transmitted through the soil. Controlling the volume of the pumped material, a calculated stress-strain state of the soil massif is created, which ensures safe construction. The article contains theoretical foundations describing the processes and examples of numerical simulation of control processes of the stress-strain state of the base when tunneling under the building.
\end{abstract}

\section{Introduction}

The most advanced form of compensatory injection [1-3] is carried out by the wristband technology, when the injection special solute is pumped into the soil through injectors into the indicated levels of injection, the design of which allows processing the soil in height repeatedly, in any sequence.

The method of compensatory injection conditionally has 4 main stages:

The first stage (preliminary injection) is an injection method for creating a stable enclosing array by impregnating its capillary-porous structure with a high-permeability solution. At the base of the structure is formed the massif with isotropic properties, while the deformation properties (deformation modulus, Poisson's ratio) increase with the array in comparison with its original physical and mechanical properties due to the decrease in the porosity coefficient, which leads to an increase in the efficiency of the system, due to smaller losses on the compressible thickness, as well as by increasing the coefficient of lateral pressure (respectively, and horizontal stresses), which leads to a change in the form of the pumped solution to the more compressed.

Second stage (compensatory injection) - injection of a jack suspension to form a prestress in the ground and create a preventive rise up to $1-5 \mathrm{~mm}$.

\footnotetext{
* Corresponding author: vitsid@mail.ru
} 
Stage 3 (compensatory injection) - injection of the "jack" suspension is combined with tunneling or other impact, providing a controlled process of suppressing the relaxation of the structure when deformations occur.

The fourth stage (stabilization of the structure) - the injection of the "jack" suspension is performed as the settlement deformations develop due to the preservation of stress relaxation in the soil volume, which ensures the design positions of the structure.

Mechanically, the injection process is an expansion of the volume of the soil surrounding the injector, that is, the appearance of positive volume deformations in it. The processes of borehole expansion and changes in the initial stress-strain state have a theoretical description that allows predicting the change of its individual components. [4-6]

\section{Analytical solution}

For solving the problem of expanding the initial volume analytically it is necessary to determine the radial $\sigma_{r}$ and tangential $\sigma_{\theta}$ stress at the pile-soil contact with increasing the borehole diameter by a given value of $u$. Thus, by setting the size of the volume expansion $u_{\kappa}$, we will determine the stresses in the surrounding soil massif (Figure 1).

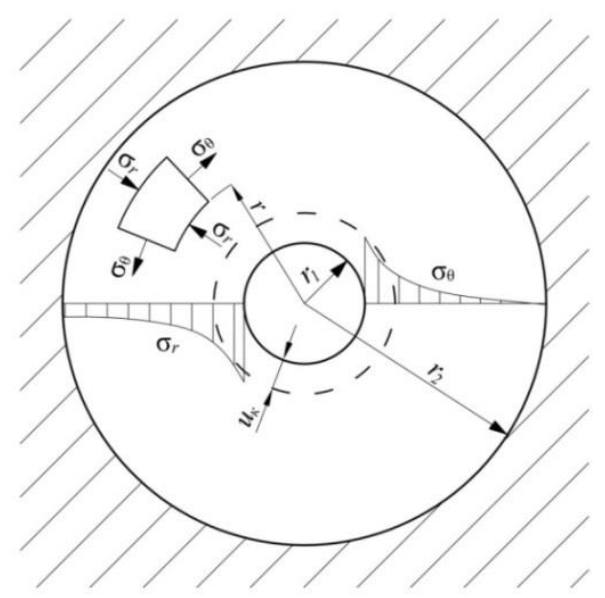

Fig. 1. Scheme of expansion of the diameter of the initial volume during the compensation process

The formulation and solution of the problem are considered in polar coordinates under the conditions of a plane stress state, i.e. when $\sigma_{z}=0$. Equation of equilibrium for a $1 \mathrm{~m}$ of expanding volume takes the form:

$$
\sigma_{r}-\sigma_{\theta}+r \frac{d \sigma_{r}}{d r}=0
$$

where $r$ - distance between the axis of symmetry and the point under consideration.

Taking into account the transformations, equation (1) in displacements form is as follows [7]:

$$
\frac{d^{2} u}{d r^{2}}+\frac{1}{r} \frac{d u}{d r}-\frac{u}{r^{2}}=0,
$$

where $u$-displacement in radial direction.

The relationship between stresses and displacements has the form [7-9]: 


$$
\begin{gathered}
\sigma_{r}=\frac{E}{1-v^{2}}\left(\frac{d u}{d r}+v \frac{u}{r}\right) \\
\sigma_{r}=\frac{E}{1-v^{2}}\left(\frac{u}{r}+v \frac{d u}{d r}\right),
\end{gathered}
$$

where $v, E$ - deformation parameters of the soil.

The general solution of equation (2) is written in the form:

$$
u=A r+\frac{B}{r}
$$

where $\mathrm{A}, \mathrm{B}$ - are integration constants determined from the boundary conditions:

$$
\left\{\begin{array}{l}
u\left(r=r_{1}\right)=u_{k} \\
u\left(r=r_{2}\right)=0
\end{array}\right.
$$

where $r_{1}$ - radius of the volume; $r_{2}$ - radius of the influence zone; $u_{k}$ - expansion of the volume radius.

Substituting (6) into (5), we obtain:

$$
\begin{aligned}
& A r_{1}+\frac{B}{r_{1}}=u_{k} \\
& A r_{2}+\frac{B}{r_{2}}=0
\end{aligned}
$$

Solving the system (7) and (8), we can find the integration constants:

$$
\begin{gathered}
A=\frac{u_{k} \cdot r_{1}}{r_{1}^{2}-r_{2}^{2}} \\
B=-\frac{u_{k} \cdot r_{1} \cdot r_{2}^{2}}{r_{1}^{2}-r_{2}^{2}}
\end{gathered}
$$

The expression (5) taking into account (9) and (10) takes the form:

$$
u(r)=\frac{u_{k} r_{1}}{r_{1}^{2}-r_{2}^{2}}\left(r-\frac{r_{2}^{2}}{r}\right)
$$

Using (11), it's possible to define the stresses in the soil massif with allowance for (3):

$$
\begin{aligned}
& \sigma_{r}(r)=\frac{E}{1-v^{2}} \cdot \frac{u_{k} \cdot r_{1}}{r_{1}^{2}-r_{2}^{2}} \cdot\left[1+v+\frac{r_{2}^{2}}{r^{2}}(1-v)\right] \\
& \sigma_{\theta}(r)=\frac{E}{1-v^{2}} \cdot \frac{u_{k} \cdot r_{1}}{r_{1}^{2}-r_{2}^{2}} \cdot\left[1+v+\frac{r_{2}^{2}}{r^{2}}(1-v)\right]
\end{aligned}
$$




$$
\sigma_{r}(r)-\sigma_{\theta}(r)=\frac{4 G \cdot u_{k} r_{1} r_{2}^{2}}{\left(r_{1}^{2}-r_{2}^{2}\right) r^{2}}
$$

\section{Numerical solution}

The main task of numerical simulation is the selection of such a volume of injected mixture in the base area in order to achieve the maximum degree of influence on its changing stressstrain state (the process of compensating of the settlement received by the building) or the maximum degree of protection of the building against impacts coming through the soil.

As an example of taking into account compensatory injection into the base, the numerical calculation is described that was carried out to find the optimal volume of mixture injection into the base of the existing building, under which the tunnel was to be constructed with an external diameter of $10.69 \mathrm{~m}$ (Figure 2).

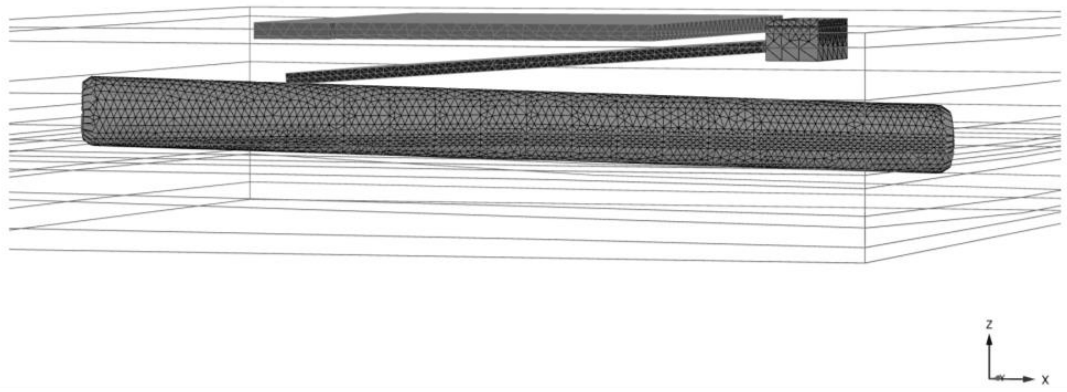

Fig. 2. Estimated finite-element scheme of the soil massif including building, structures for the production of compensatory injection and a the tunnel (soil visualization is disabled)

In the process of calculation, it is possible to distinguish two main causes of tunnel construction influence on the stress-strain state of the base of the existing building. The first is to simulate the excavation of the soil itself within the tunnel section, which determines the unloading of the soil around the tunnel and the deformation of its arranged lining. The second cause of deformations of the base is the modeling of soil contraction, which takes place during shield excavation and is usually the cause of sufficiently large soil movements even at the level of relief. Based on the known data on the influence of tunnel excavation on buildings under similar conditions, the contraction value was $1.8 \%$ [10-14].

During the calculation, the following stages of tunneling were modeled:

- loading of the calculated array with the own weight of the soil and determining its initial stress-strain state;

- inclusion of the existing building in the calculation area, determination of the stressstrain state of its soils;

- simulation of arising of the impregnation injection zone;

- modeling of tunneling taking into account soil removal and soil contraction (10 stages);

- simulation of the compensation injection zone operation, taking into account the tunnel excavation zones (10 steps). 

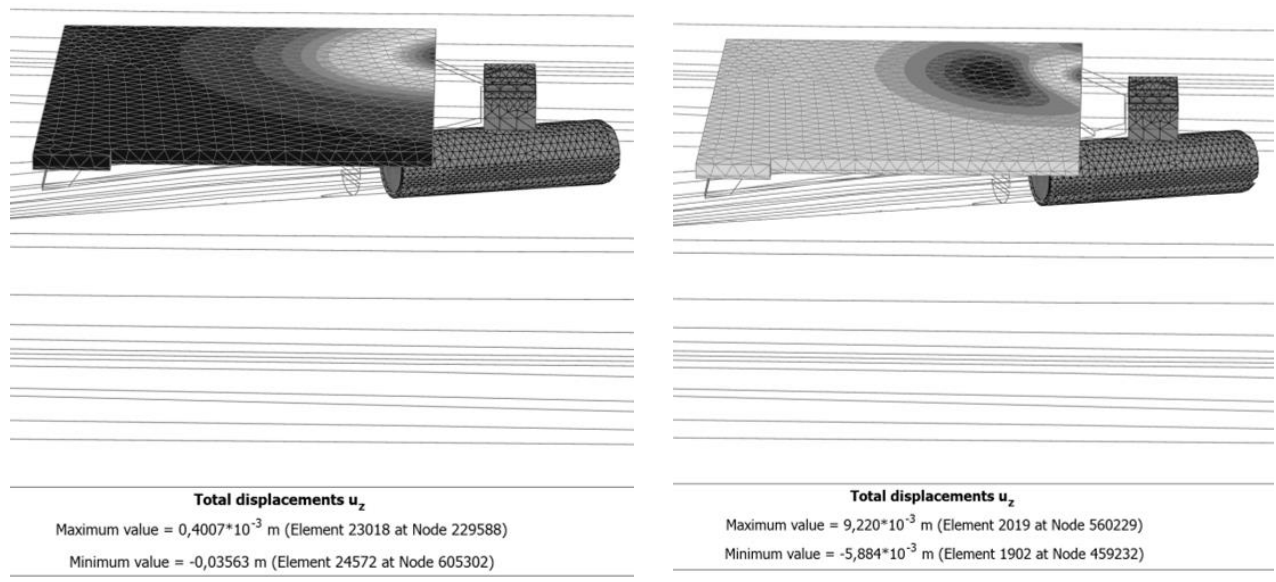

Fig. 3. The isopoles of vertical movement of the building after the first stage of excavation (left) and after compensatory injection (right)

Compensation measures were selected in such a way that the total settlement of the building did not exceed the permissible values established by regulatory documents $(3 \mathrm{~cm})$. Figure 3 shows the isopoles of displacements after tunneling and after compensatory injection in the first stage of tunneling. After passing part of the tunnel, the settlement of the building exceeded $3 \mathrm{~cm}$, but the compensation works reduced it to $6 \mathrm{~mm}$. In the same way, the modeling of the compensation of deformations was made at each stage of excavation. The average value of the required volumetric expansion for this object was 6 percent.

Figure 4 shows the resulting isopoles of the vertical movement of the building after the last stage of compensatory injection. The vertical movement of the building after the completion of all works was $15 \mathrm{~mm}$, which is below the permissible limit for the building.

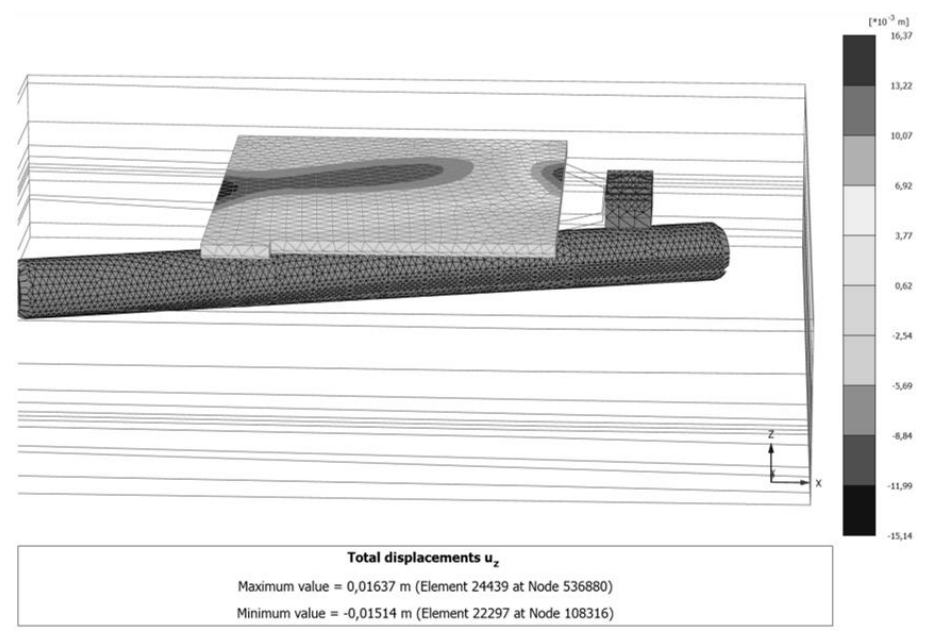

Fig. 4. The isopoles of vertical displacements of the building after the total completion of all geotechnical works at the site 


\section{Conclusions}

1. Compensatory injection into the base is a modern and effective way of controlling the stress-strain state of the foundations of existing and under construction buildings.

2. The technology of compensatory injection has an analytical basis in the form of a set of ready solutions for forecasting the change in the state of the base after its impact, and is also amenable to a numerical solution using modern geotechnical software systems.

3. The given example of numerical simulation clearly demonstrates the effectiveness of the technology, as well as the way to find the required volume of injection to compensate for deformations received by the building during construction that placed close to it.

This work was financially supported by Ministry of Education and Science of the Russian Federation (\#NSh-3492.2018.8). All tests were carried out using research equipment of The Head Regional Shared Research Facilities of the Moscow State University of Civil Engineering (RFMEFI59317X0006).

\section{References}

1. M.G. Zertsalov, A.N. Simutin, A.V. Alexandrov, Compensatory injection technology for protection of building and structures. Bulletin of MSUCE, 6, 32-40 (2015)

2. E.N. Bellendir, A.V. Aleksandrov, M.G. Zertsalov, A.N. Simutin, Building and structure protection and leveling using compensation grouting technology. Power Technology and Eng., 50, 2, 142-146 (2016)

3. I.Ya. Kharchenko, V.E. Merkin, A.N. Simutin, M.G. Zertsalov, Application of compensation grouting technology for protection of buildings and structures under construction of tunnels. Transport constr., 1, 6-9 (2015)

4. I.Ya. Kharchenko, S.V. Alekseev. Combined cementation of soils in the development of underground space in conditions of density urban development. Metro and tunnels, 5, 18-20 (2013)

5. I.Ya. Kharchenko, M.G. Zertsalov, A.N. Simutin, A.I. Kharchenko, Design and technological bases of management of stress-strain state of the soil with compensation grouting. Metro and tunnels, 5, 20-23 (2015)

6. I.Ya. Kharchenko, V.A. Alekseev, K.A. Israfilov, A.S.E. Beterbiev, Modern technologies of cementation of the soils. Bulletin of MSUCE, 5(104), 552-558 (2017)

7. N.I. Bezukhov, Bases of elastic, plastic and creep theories (High school, Moscow, 1961)

8. N.S. Bulichev, Mechanics of the underground structures (Nedra, Moscow, 1994)

9. S.S. Vyalov, Geological bases of soil mechanics (High school, Moscow, 1978)

10. A. Kambefor, Soil injection (Energy, Moscow, 1971)

11. V.V. Kravchenko, Effective technological parameters of compensation grouting in metro construction (MADI(GTU), Moscow, 2009)

12. L.V. Makovskii, Defining the parameters of the compensation injection during the construction of tunnels in difficult urban conditions. Proc. of the Designing of the automobile roads (MADI(GTU), Moscow,2009)

13. A.B. Ponomaryov, K.V. Golubev, Soil massif deformations around the grouted bearing element. Academic herald. Construction, 2, 110-112 
14. Yu. Rashendorfer, V.N. Jukov, K. Mainer Compensation grouting as a method for ensuring the stability of buildings and structures during tunneling, Metro and tunnels, 4, 26-28

15. R.F. Ganiev, S.R. Ganiev, V.P. Kasilov, A.P. Pustovgar, Wave Technology in Mechanical Engineering: Industrial Applications of Wave and Oscillation Phenomena, (Wiley, 2015)

16. K.S. Fahmi, M.Y. Fattah, A. Pustovgar, MATEC Web of Conferences, 170, 03001 (2018) 